\title{
Empirical Storm-Time Correction to the International Reference Ionosphere Model E-Region Electron and Ion Density Parameterizations Using Observations from TIMED/SABER
}

\author{
C. J. Mertens ${ }^{\mathrm{a}}$, J. R. Winick ${ }^{\mathrm{b}}$, J. M. Russell III ${ }^{\mathrm{c}}$, M. G. Mlynczak ${ }^{\mathrm{a}}$, D. S. Evans ${ }^{\mathrm{d}}$, Dieter \\ Bilitza ${ }^{\mathrm{e}}$, and $\mathrm{X} . \mathrm{Xu}^{\mathrm{f}}$ \\ ${ }^{a}$ NASA Langley Research Center, Hampton, VA USA \\ ${ }^{\mathrm{b}}$ Air Force Research Laboratories, Hanscom AFB, MA USA \\ ${ }^{\mathrm{c}}$ Hampton University, Hampton, VA USA \\ ${ }^{\mathrm{d}}$ NOAA Space Environment Center, Boulder, CO USA \\ ${ }^{\mathrm{e}}$ George Mason University, Fairfax, VAUSA \\ ${ }^{\mathrm{f}}$ SSAI, Hampton, VA, USA
}

\begin{abstract}
The response of the ionospheric E-region to solar-geomagnetic storms can be characterized using observations of infrared $4.3 \mathrm{um}$ emission. In particular, we utilize nighttime TIMED/SABER measurements of broadband $4.3 \mathrm{um}$ limb emission and derive a new data product, the $\mathrm{NO}^{+}(\mathrm{v})$ volume emission rate, which is our primary observationbased quantity for developing an empirical storm-time correction the IRI E-region electron density. In this paper we describe our E-region proxy and outline our strategy for developing the empirical storm model. In our initial studies, we analyzed a six day storm period during the Halloween 2003 event. The results of this analysis are promising and suggest that the ap-index is a viable candidate to use as a magnetic driver for our model.
\end{abstract}

\section{INTRODUCTION}

Observations of thermospheric infrared emission from the TIMED/SABER instrument have fostered the development of new data products, models, and analysis tools for the study of upper atmospheric and ionospheric response to solar-geomagnetic disturbances. The focus of this paper is on analyzing SABER $4.3 \mathrm{um}$ limb emission measurements to quantify the E-region response to solar-geomagnetic storms, with the objective of developing an empirical E-region storm-time correction to the International Reference Ionosphere (IRI) model (Bilitza, 2001).

The Sounding of the Atmosphere using Broadband Emission Radiometry (SABER) instrument is a broadband infrared limb sounder on the Thermosphere-IonosphereMesosphere-Energetics and Dynamics (TIMED) satellite (Russell et al., 1999). TIMED was launched in 2001 and has observed the atmospheric response to several major solar eruptive events. Specific to this paper, SABER observed enhancements in the nighttime $4.3 \mathrm{um}$ limb emission channel by several orders of magnitude during the April 2002 and October-November ("Halloween") 2003 storm period, for example. The storm-time enhancements in the nighttime 4.3 um radiances are due to emission from vibrationally excited $\mathrm{NO}^{+}$, i.e. $\mathrm{NO}^{+}(\mathrm{v})$ (Mertens et al., 2007). Precipitating auroral electrons during solar-geomagnetic disturbances increase the production of ions via ionization of the 
neutral atmosphere (Banks et al., 1974; Strickland et al., 1976). In the E-region, these ions react with neutral species to produce $\mathrm{NO}^{+}$(Torr et al., 1990; Fox and Sung, 2001). Some of the ion-neutral reactions are exothermic enough to produce $\mathrm{NO}^{+}(\mathrm{v})$, which emits at $4.3 \mathrm{um}$ (Winick et al., 1987). The $\mathrm{NO}^{+}(\mathrm{v})$ component of the total $4.3 \mathrm{um}$ emission is extracted from the SABER measurements by subtracting off the $\mathrm{CO}_{2}\left(\mathrm{v}_{3}\right)$ contribution using non-LTE radiation transfer algorithms and input atmospheric data from SABER measurements, combined with the NRLMSIS-00 model (Mertens et al., 2007, 2002, 2001). Since $\mathrm{NO}^{+}$is the terminal E-region ion, $\mathrm{NO}^{+}(\mathrm{v}) 4.3 \mathrm{um}$ emission is an excellent proxy to characterize the response of the E-region to solar-geomagnetic storms. Moreover, by charge neutrality, $\mathrm{NO}^{+}(\mathrm{v})$ emission is also an indication of the response of the E-region electron density to magnetic storms. We will exploit these properties of the E-region in our development of an empirical storm-time correction to the IRI model Eregion electron density.

The IRI model is a widely used empirical model for the specification of ionospheric parameters and is recommended for international use by the Committee on Space Research (COSPAR) and the International Union of Radio Science (URSI). However, the specification of the ionospheric response to solar-geomagnetic disturbances in IRI remains largely incomplete, and there is currently no storm-time correction to IRI parameters in the E-region. An error of several orders of magnitude in the IRI E-region parameterization will limit the model's usability in radio wave propagation models - as applied to system design of communication, navigation, and surveillance systems - and real-time processing of the radio wave propagation data during solar-geomagnetic storms. Errors in E-region electron density of several orders of magnitude can induce nonnegligible errors in modeling vertical and slant path radio wave propagation (satellite to ground communication). Moreover, significant errors can be induced in modeling satellite to satellite radio wave propagation along long horizontal paths. To improve the utility and range of applicability of the IRI model, we have initiated a plan to develop an empirical storm-time correction to the IRI E-region electron density using SABER 4.3 um limb radiance measurements.

In this paper we describe the parameterization of the storm-time correction to the IRI Eregion electron density using observations from TIMED/SABER 4.3 um limb emission measurements. Our E-region proxy derived from the SABER observations is the $\mathrm{NO}^{+}(\mathrm{v})$ volume emission rate (VER), which is described in section 2. The parameterization of Eregion electron density enhancements due to solar-geomagnetic forcing, based on the $\mathrm{NO}^{+}(\mathrm{v}) \mathrm{VER}$, is described in section 3. Analysis of several magnetically disturbed days during the Halloween 2003 storm period, as presented in section 4, provide considerable guidance on the selection of (1) the external magnetic driver index, and (2) the form of the impulse-response function, both of which are key ingredients in the formulation of the parameterization of the storm-time correction to the IRI E-region electron density. A summary of our initial studies is presented in section 5 .

\section{E-REGION PROXY: $\mathrm{NO}^{+}(\mathrm{v})$ VER}


As discussed in the introduction, $\mathrm{NO}^{+}(\mathrm{v}) 4.3 \mathrm{um}$ emission is an excellent proxy for characterizing the response of the E-region to solar-geomagnetic disturbances. Specifically, we derive $\mathrm{NO}^{+}(\mathrm{v})$ VER from the SABER 4.3 um limb emission measurements.

The first step to derive $\mathrm{NO}^{+}(\mathrm{v})$ VER is to subtract the background $\mathrm{CO}_{2}\left(\mathrm{v}_{3}\right)$ emission from the measured $4.3 \mathrm{um} \mathrm{limb}$ radiance. This is accomplished with the radiation transfer algorithms used in the operational processing of the SABER data. The $\mathrm{CO}_{2}\left(\mathrm{v}_{3}\right)$ contribution is removed using the $4.3 \mathrm{um}$ forward radiance component of the operational non-local thermodynamic equilibrium (non-LTE) kinetic temperature (Tk) and $\mathrm{CO}_{2}$ volume mixing ratio (vmr) retrieval algorithm (Mertens et al., 2001, 2002). The forward model is comprised of two parts: (1) the $\mathrm{CO}_{2}$ vibrational temperature (Tv) model and (2) the limb radiance model. Limb radiance is calculated using BANDPAK (Marshall et al., 1994), which is based on emissivity databases calculated line-by-line using LINEPAK routines (Gordley et al., 1994). The $\mathrm{CO}_{2} \mathrm{Tv}$ model is based on the Modified Curtis Matrix approach (Lopez-Puertas et al., 1986a-b, 1998), and uses BANDPAK in all the radiation transfer calculations.

The nighttime $\mathrm{CO}_{2}\left(v_{3}\right)$ contribution to the SABER-measured 4.3 um limb emission is simulated with the non-LTE radiation transfer algorithms described above using input atmospheric data from SABER-retrieved Tk and pressure, $\mathrm{CO}_{2}$ vmr from a TIME-GCM climatological database (Roble et al., 1995), and composition data $\left(\mathrm{N}_{2}, \mathrm{O}_{2}, \mathrm{O}\right)$ from the NRLMSIS-00 model (Picone et al., 2002). All input composition data $\left(\mathrm{CO}_{2}, \mathrm{~N}_{2}, \mathrm{O}_{2}, \mathrm{O}\right)$ to the $\mathrm{CO}_{2} \mathrm{Tv}$ model for the nighttime $4.3 \mathrm{um}$ limb radiance calculations are consistent with the operational processing of SABER data below $120 \mathrm{~km}$. Above $120 \mathrm{~km}$ Tk and composition are obtained from the NRLMSIS- 00 model $\left(\mathrm{CO}_{2}\right.$ still comes from the TIMEGCM database). Pressure is extended above $120 \mathrm{~km}$ assuming hydrostatic equilibrium.

The OH(v) VER data product from the SABER 2.0 um channel measurement is used to calculate the vibrational excitation of $\mathrm{N}_{2}(1)$ from collisions of ground state $\mathrm{N}_{2}$ with $\mathrm{OH}(\mathrm{v} \leq 9)$. The method of calculating the total production rate of $\mathrm{OH}(\mathrm{v})$ from measured $\mathrm{OH}(\mathrm{v})$ VER at $2.0 \mathrm{um}$ is by Mlynczak et al. (1998), while the method of calculating the rate of production of $\mathrm{N}_{2}(1)$ from $\mathrm{OH}(\mathrm{v})$ is by Lopez-Puertas et al. (2004). Energy transfer from vibrationally excited $\mathrm{OH}$ (i.e., $\mathrm{OH}(\mathrm{v} \leq 9)$ ) to $\mathrm{N}_{2}(1)$, and then to $\mathrm{CO}_{2}\left(\mathrm{v}_{3}\right)$ via a $\mathrm{V}-\mathrm{V}$ transfer mechanism, is an important source of nighttime $\mathrm{CO}_{2} 4.3$ um emission starting from $70 \mathrm{~km}$ and extending to above $120 \mathrm{~km}$ (Lopez-Puertas et al., 2004). The influence of this excitation process extends well above the $\mathrm{OH}$ layer due to the non-LTE process of local excitation $\left(\mathrm{OH}(\mathrm{v} \leq 9) \rightarrow \mathrm{N}_{2}(1) \rightarrow \mathrm{CO}_{2}\left(v_{3}\right)\right)$ followed by radiative loss and reabsorption at higher altitudes.

Once the nighttime $\mathrm{CO}_{2}\left(\mathrm{v}_{3}\right) 4.3 \mathrm{um}$ limb radiance is calculated, it is subtracted from the SABER 4.3 um radiance measurement. The residual radiance is emission from $\mathrm{NO}^{+}(\mathrm{v})$. The second step to deriving the $\mathrm{NO}^{+}(\mathrm{v})$ VER is to perform an Abel inversion on the residual radiance. An example of the $\mathrm{NO}^{+}(\mathrm{v})$ VER from the April 2002 and Halloween 2003 storm periods is shown in Figure 1. The significant enhancement of $\mathrm{NO}^{+}(\mathrm{v})$ VER during the storm periods is clearly evident. Note also that the peak in the storm-enhanced 
$\mathrm{NO}^{+}(\mathrm{v})$ occurs roughly between $\sim 100-110 \mathrm{~km}$, which is consistent with the altitude of the peak in the E-region electron density.

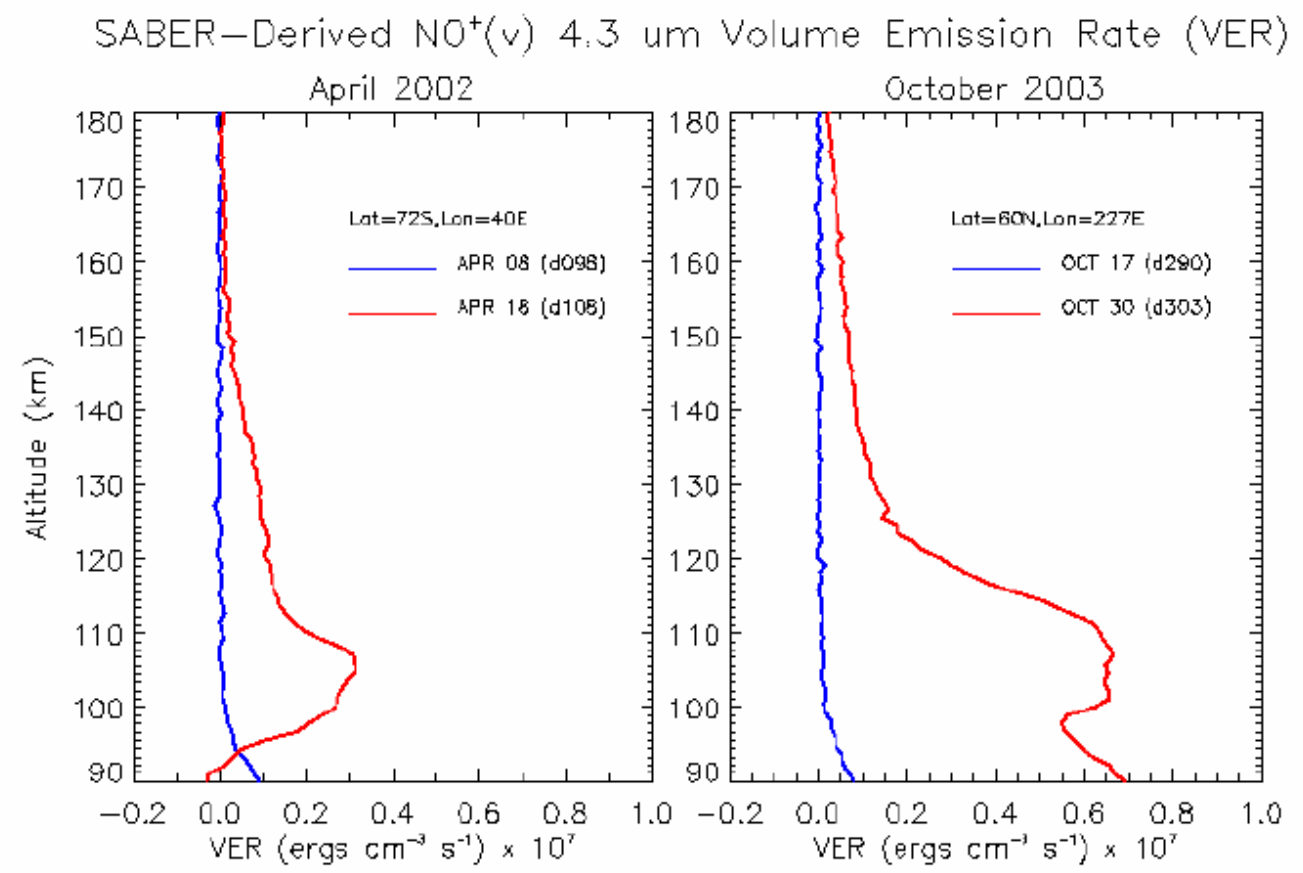

Figure 1: SABER-derived $\mathrm{NO}^{+}(\mathrm{v})$ VER for representative days prior to and during the April 2002 and Halloween 2003 solar storms. The blue lines correspond to $\mathrm{NO}^{+}(\mathrm{v})$ VER prior to the storms, while the red lines correspond to $\mathrm{NO}^{+}(\mathrm{v})$ VER during the storms. Figure taken from Mertens et al. (2007).

\section{EMPIRICAL MODEL PARAMETERIZATION}

The empirical storm-time correction to the IRI E-region electron density is based upon deriving a storm-induced correction factor from the SABER-derived $\mathrm{NO}^{+}(\mathrm{v}) \mathrm{VER}$, and developing a fit of the correction factor to an appropriate external magnetic driver index. The motivation for this approach is that it has been successfully applied to characterizing the response of a number of geospace parameters to external drivers (e.g., Fuller-Rowell et al., 2000; Vassiliadis et al., 2002).

The correction factor is defined as the ratio of the storm-time $\mathrm{NO}^{+}(\mathrm{v})$ VER to a quiettime, climatological $\mathrm{NO}^{+}(\mathrm{v}) \mathrm{VER}$, such that the correction factor is given by (Mertens et al., 2007)

$$
r\left(z, \lambda_{m}, \varphi_{m}, t\right)=\left[\operatorname{VER}\left(z, \lambda_{m}, \varphi_{m}, t\right)\right]_{\text {Storm }} /\left[\operatorname{VER}\left(z, \lambda_{m}, \varphi_{m}\right)\right]_{\text {Quiet }} .
$$


In the above equation, $V E R$ refers to $\mathrm{NO}^{+}(\mathrm{v}) \mathrm{VER}, \lambda_{m}$ is magnetic latitude, and $\varphi_{m}$ is magnetic local time. The quiet-time, climatological $\mathrm{NO}^{+}(\mathrm{v}) \mathrm{VER}$ are monthly-averaged quantities. Results from SABER 4.3 um radiance measurements, NOAA/POES auroral electron energy characteristics in-situ observations, charge neutrality, and model simulations of the ionospheric plasma, $\mathrm{NO}^{+}(\mathrm{v})$ chemical and radiative energetics, suggests the $\mathrm{NO}^{+}(\mathrm{v})$ VER ratio in (1) is approximated by

$$
r\left(z, \lambda_{m}, \varphi_{m}, t\right) \approx \frac{\left[N O^{+}\right]_{\text {Storm }}}{\left[N O^{+}\right]_{\text {Quiet }}} \approx \frac{[e]_{\text {Storm }}}{[e]_{\text {Quiet }}}
$$

where [e] is the electron density. The $\mathrm{NO}^{+}(\mathrm{v})$ VER ratio will be computed for all magnetically disturbed periods contained in the SABER dataset from 2002-2007.

The computed storm-time correction factors in (1) are fit to a polynomial expansion in a magnetic forcing parameter $(\mathrm{G})$, such that

$$
r\left(z, \lambda_{m}, \varphi_{m}, t\right)=\sum_{i=0}^{N} a_{i}\left(z, \lambda_{m}, \varphi_{m}\right) G^{i}\left(z, \lambda_{m}, \varphi_{m} ; t\right)
$$

where $a_{i}$ are the expansion coefficients. The magnetic forcing parameter $(\mathrm{G})$ captures the dynamical response of the E-region by representing the forcing parameter as a convolution of an external magnetic driver index (D) with a dynamical response function $(F(\tau))$. Thus, the forcing parameter is given by

$$
G\left(z, \lambda_{m}, \varphi_{m} ; t\right)=\int_{-T_{s}}^{T} F\left(z, \lambda_{m}, \varphi_{m} ; \tau\right) D(t-\tau) d \tau
$$

The effective memory of the storm-time response of the E-region corresponds to time (T) in the upper limit of the integral in (4). The lower limit of the integral (Ts) represents the start time and is chosen to ensure numerical stability in solving for the response function $(F(\tau)$ ). Both upper and lower integration limits can be established by examining the cross correlation function presented in section 4.

To develop the empirical storm-time correction model, one must select an appropriate external magnetic driver index (D). To be of practical value to the broad space weather community, and for easily implementation into the IRI model, the external magnetic driver index must be a widely known, easily accessible index. Some obvious indices to choose from are the Hemispheric Power index (HP), Disturbed Storm Time (Dst) index, ap index, and the Auroral Electrojet (AE) index. The selection of the appropriate magnetic driver index is discussed further in the next section. On the other hand, once the magnetic driver index is chosen, the response function can be readily determined by 


$$
r\left(z, \lambda_{m}, \varphi_{m}, t\right)=\int_{-T_{s}}^{T} F\left(z, \lambda_{m}, \varphi_{m} ; \tau\right) D(t-\tau) d \tau
$$

The above equation assumes a linear impulse-response relation between the external driver index and the response of the E-region ionosphere, as characterized by the $\mathrm{NO}^{+}(\mathrm{v})$ VER ratio. The $\mathrm{NO}^{+}(\mathrm{v})$ VER ratios for all magnetically disturbed periods in the SABER dataset from 2002-2007 are used to solve for the response function $(F(\tau))$ in (5). The integral in (5) is discretized and formulated in terms of a matrix-vector equation. The response function is determined by inverting the equivalent matrix-vector equation using Singular Value Decomposition (SVD) techniques (Press et al., 1992). Any residual nonlinearity between the driver (D) and the response (r) is accounted for by non-linear terms in the polynomial expansion in (3).

\section{ANALYSIS OF THE HALLOWEEN 2003 STORM}

In this section we analyze six days during the Halloween storm period, October 27November 1, 2003. The data volume based on six days is insufficient to develop the statistical parameterization presented in the previous section, yet this limited analysis provides considerable guidance into the selection of magnetic driver and insight into the form of the response function.

To obtain a global perspective on the response of the E-region during the Halloween 2003 storm period we show the SABER-derived $\mathrm{NO}^{+}(\mathrm{v})$ VER at $110 \mathrm{~km}$ in Figure 2. Large enhancements are noticeable on all of the days shown in Figure 2. The morphology of the peak $\mathrm{NO}^{+}(\mathrm{v}) \mathrm{VER}$ is consistent with the shape of the auroral oval due to electron precipitation (not shown). Exceptional equatorward expansions of the auroral oval are clearly evident on 29-30 October.

Guidance into the selection of the magnetic driver index can be obtained by computing the cross correlation function between the SABER-derived $\mathrm{NO}^{+}(\mathrm{v}) \mathrm{VER}$ and the candidate magnetic driver index. The cross correlation function is defined as (Vassiliadis, 2002)

$$
C\left(\lambda_{m}, \tau\right)=\frac{1}{T} \frac{1}{\sigma_{D} \sigma_{V E R}} \sum_{i=1}^{T}\left(\operatorname{VER}\left(\lambda_{m}, t_{i}+\tau\right)-\left\langle\operatorname{VER}\left(\lambda_{m}\right)\right\rangle\right)\left(D\left(t_{i}\right)-\langle D\rangle\right) .
$$

The data volume for the six day analysis period (October 27-November 1, 2003) is insufficient to determine a dependence on magnetic local time. Thus, the $\mathrm{NO}^{+}(\mathrm{v}) \mathrm{VER}$ data during the six day period were sorted and averaged into 5 degree bins in magnetic latitude. Both the $\mathrm{NO}^{+}(\mathrm{v}) \mathrm{VER}$ and the magnetic driver indices were sorted an averaged into 3 hour UT-time bins throughout the duration of the six day storm period. The summation in (6) is over all the 3 hour UT-time bins over the six day storm period. The average values (denoted by $<>$ ) were computed over the six day period and the standard 
deviation (denoted by $\sigma$ ) were computed about the average values.

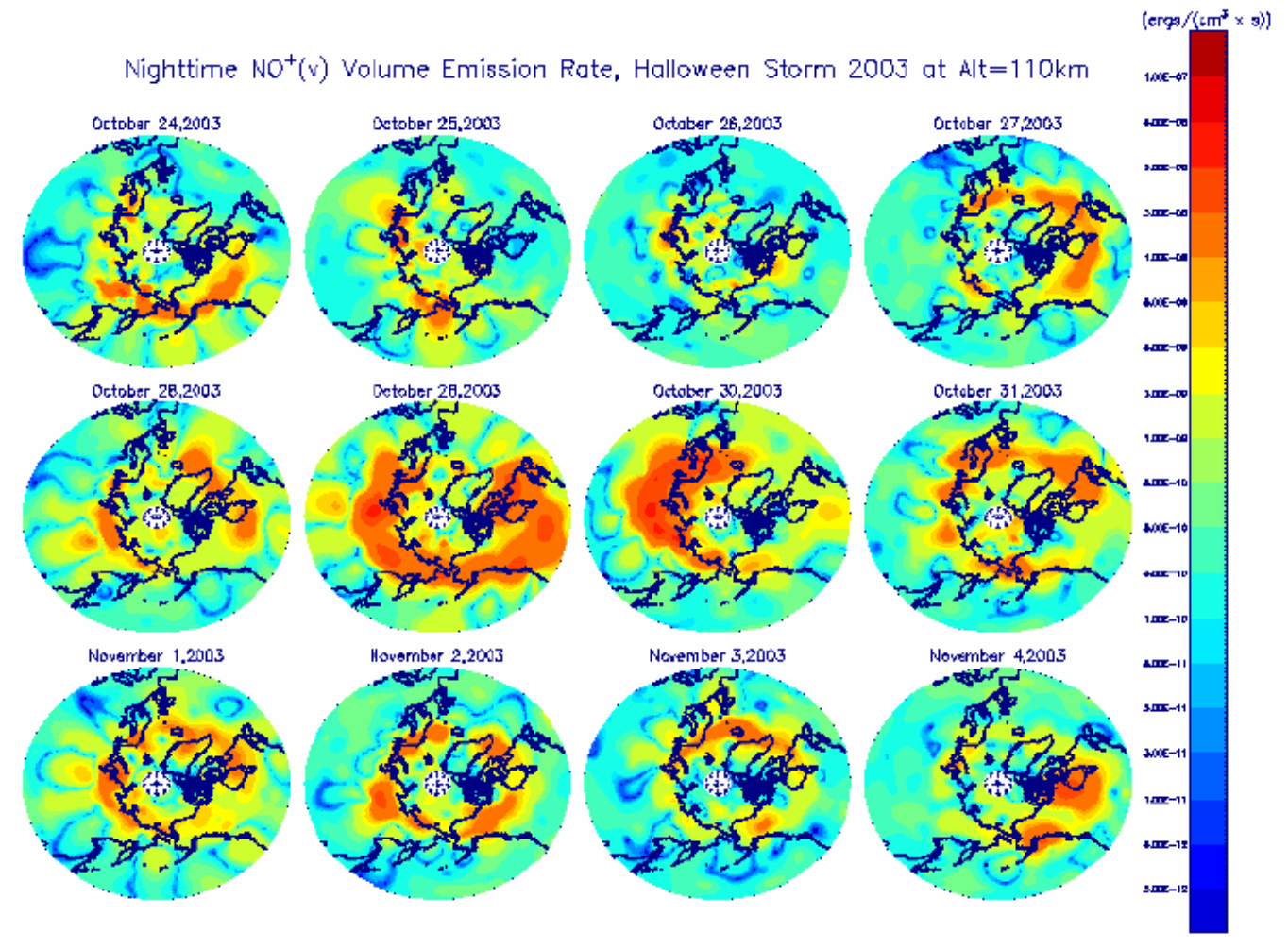

Figure 2: : SABER-derived $\mathrm{NO}^{+}(\mathrm{v})$ VER at $110 \mathrm{~km}$ during a select period of the Halloween 2003 solar storm event. The unit for the VER is ergs $\mathrm{cm}^{-3} \mathrm{~s}^{-1}$.

Figure 3 shows the cross correlation function between $\mathrm{NO}^{+}(\mathrm{v}) \mathrm{VER}$ and the Hemispheric Power (denoted HP: unit is GW) index derived from NOAA/POES measurements of auroral electron precipitation. Since the HP-index most likely represents to the physical source mechanism for the response of the E-region to solar-geomagnetic storms, we consider this correlation to be a benchmark for evaluating the "goodness" of more readily available solar-geomagnetic storm indices. Figure 3 indicates that the peak correlation of $\sim 0.60$ for altitudes at and below $110 \mathrm{~km}$ occurs between 50 and 60 degrees magnetic latitude, and occurs instantaneously or with delay times of the order of $\sim 3$ hours UT. At and above $110 \mathrm{~km}$ the peak value of the cross correlation extends down to $\sim 30-35$ degrees magnetic latitude, and tilts to the right with increasing delay time. This is likely an indication of composition changes in the region of auroral electron dosing, which are then transported equatorward.

We have computed the cross correlation function between $\mathrm{NO}^{+}(\mathrm{v})$ VER and the Dstindex (not shown). The Dst-index is indicative of perturbations of the horizontal component of the geomagnetic field at the magnetic equator due to storm-time disturbances of the ring current. The perturbation in the horizontal magnetic field component could potentially alter the mapping of the auroral particles into the atmosphere at mid- and high-latitude, and subsequently influence the response of the E- 
region to auroral particle precipitation. The cross correlation between $\mathrm{NO}^{+}(\mathrm{v}) \mathrm{VER}$ and Dst-index has a similar morphology as shown in Figure 3, but the magnitude of the correlation as far less than between $\mathrm{NO}^{+}(\mathrm{v})$ VER and HP-index.

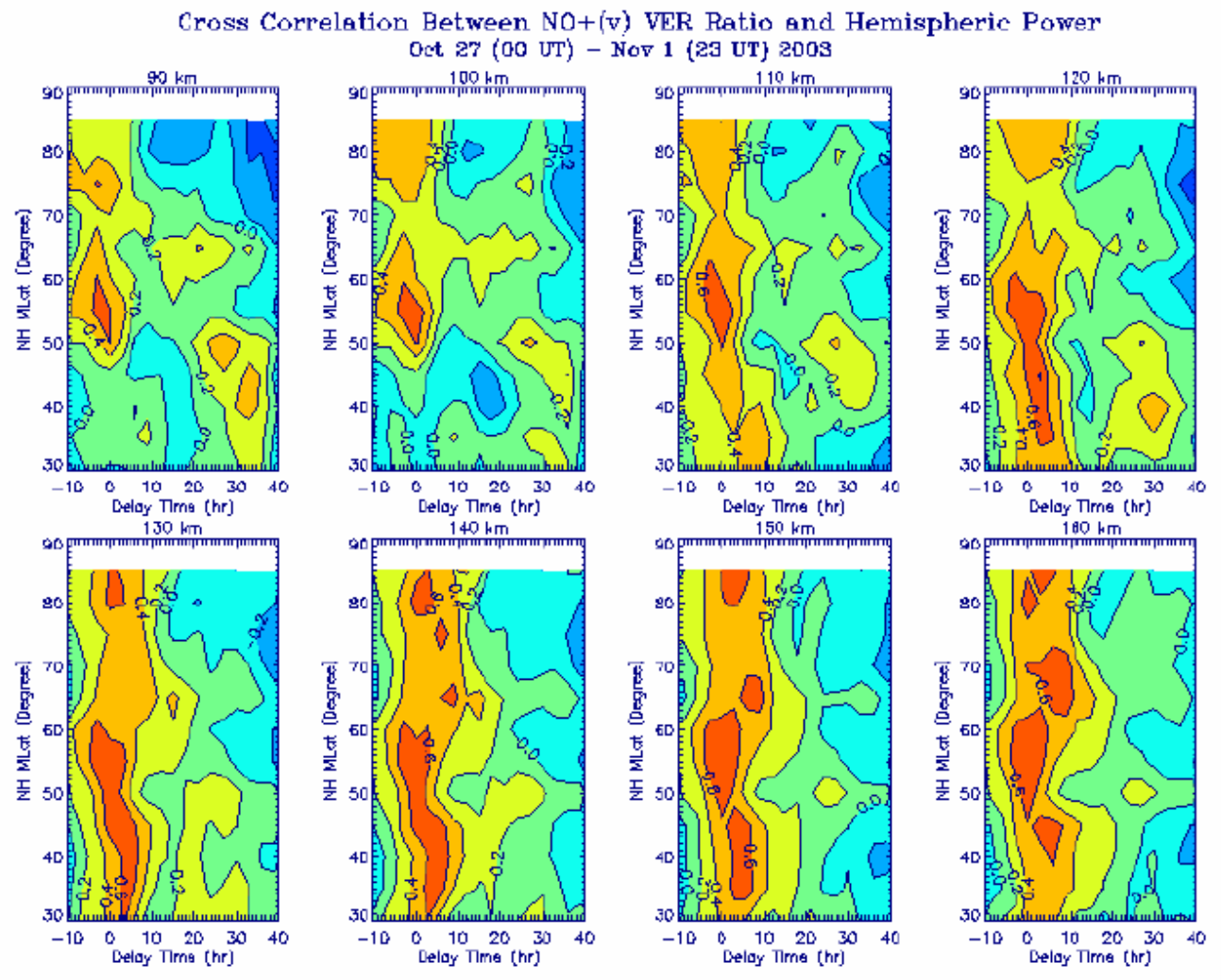

Figure 3: Cross correlation between SABER-derived $\mathrm{NO}^{+}(\mathrm{v})$ VER and Hemispheric Power (denoted HP: unit is GW) index derived from NOAA/POES satellites. Each panel shows the cross correlation function as a function of magnetic latitude and delay time (hours). The different panels correspond to different altitudes. The cross correlation function is defined in the text.

Figure 4 shows the cross correlation between $\mathrm{NO}^{+}(\mathrm{v}) \mathrm{VER}$ and the ap-index. The correlation between these two quantities is comparable to the correlation between $\mathrm{NO}^{+}(\mathrm{v})$ VER and the HP-index. This is a fortunate result because the ap-index is readily accessible and the IRI model already includes the ap-index as an input. We haven't examined the AE-index yet, but we expect this index to be very useful as well, particularly at the higher latitudes.

Figure 5 shows the solution for the response function based on the six days analyzed during the Halloween storm period. The results are very noise due to the small data volume. However, a reasonable pattern can be discerned which is consistent with the cross correlation functions shown in Figures 3 and 4. Poleward of 50 degrees magnetic latitude, where the largest enhancements occur, a peak in the response functions occurs between zero and a $\sim 3$ hour UT delay time. This is consistent with the delay times indicated by the cross correlation functions in Figure 3 and 4. For larger delay time the 
response function oscillates through zero and eventually drifts positive. We expect that when we analyze all the magnetic storm periods in the SABER database from 2002-2007 the peak in the response function at zero to 3 hour UT delay time will dominate and the response function will quickly decay to zero with small oscillations about zero.

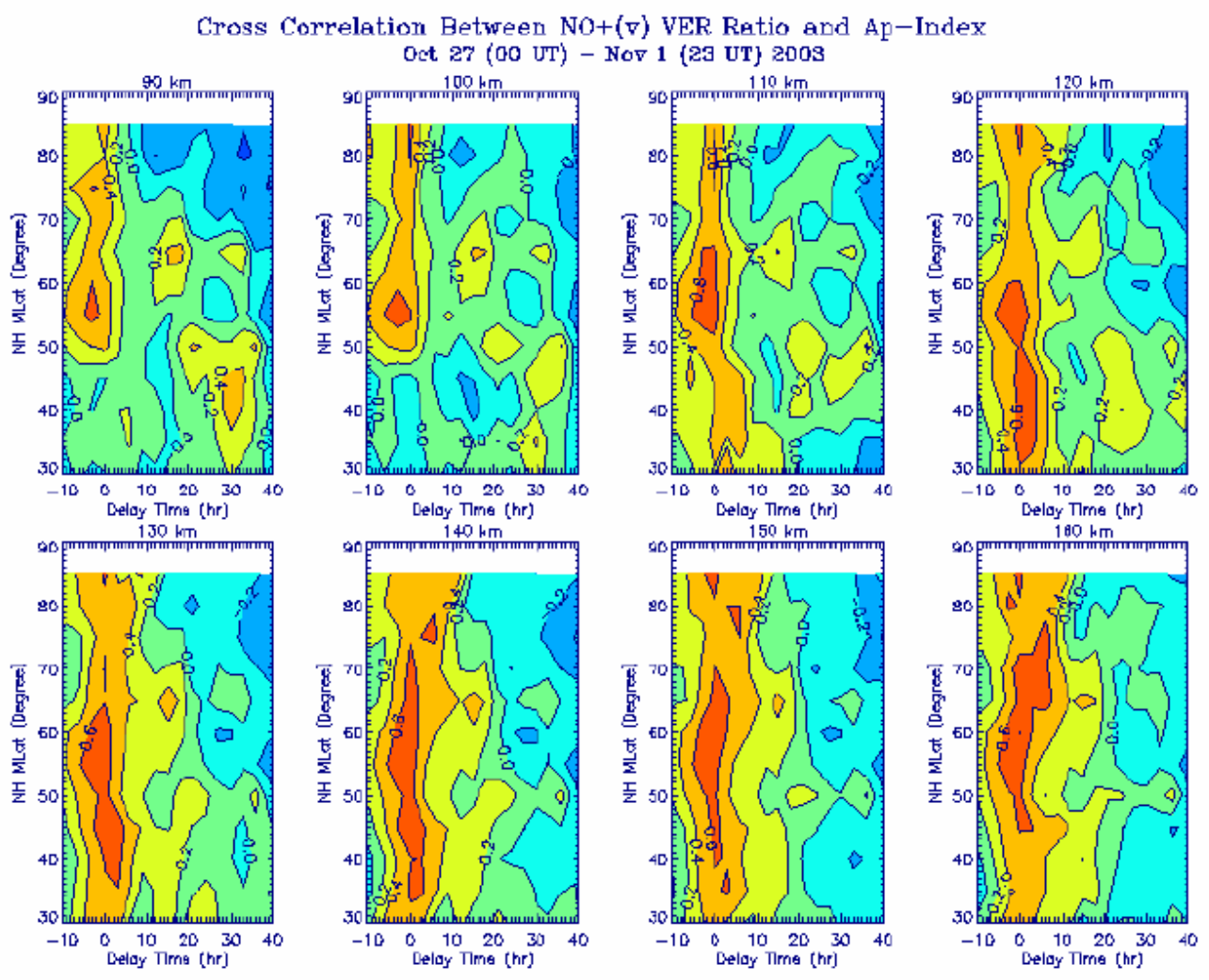

Figure 4: Cross correlation function between SABER-derived $\mathrm{NO}^{+}(\mathrm{v})$ VER and the ap-index. Each panel shows the cross correlation function as a function of magnetic latitude and delay time (hours). The different panels correspond to different altitudes. The cross correlation function is defined in the text.

\section{SUMMARY}

The $\mathrm{NO}^{+}(\mathrm{v})$ VER derived from SABER 4.3 um limb emission measurements provide an excellent proxy for characterizing the response of the ionospheric E-region to solargeomagnetic storms. Storm-time observations from SABER and NOAA/POES, combined with the known physics and chemistry of the E-region, suggest that the $\mathrm{NO}^{+}(\mathrm{v})$ VER also contains valuable information about the response of the E-region electron density to solar-geomagnetic disturbances. Thus, we have initiated a program to develop an empirical storm-time correction to the IRI E-region electron density based on $\mathrm{NO}^{+}(\mathrm{v})$ VER derived from SABER. Our storm model will potentially enhance the capability of the widely used IRI model and increase its usability in real-time space weather applications. Preliminary analysis of a six day storm period during the Halloween 2003 
event suggests that the ap-index is a viable candidate for an external magnetic driver for our empirical model. Additional storm indices will be examined in the future. Moreover, we will analyze over 80 storm days observed in the SABER dataset from 2002-2007. The results of this analysis will provide the input to develop the final form of our empirical storm model, which will be the subject of future reports.

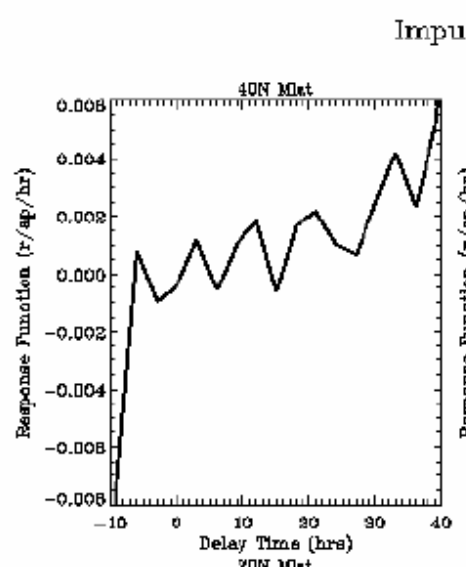

Impulse Response Function Derived at $110 \mathrm{~km}$ Oct 27 (00 UT) - Nov 1 (29 UT) 2003
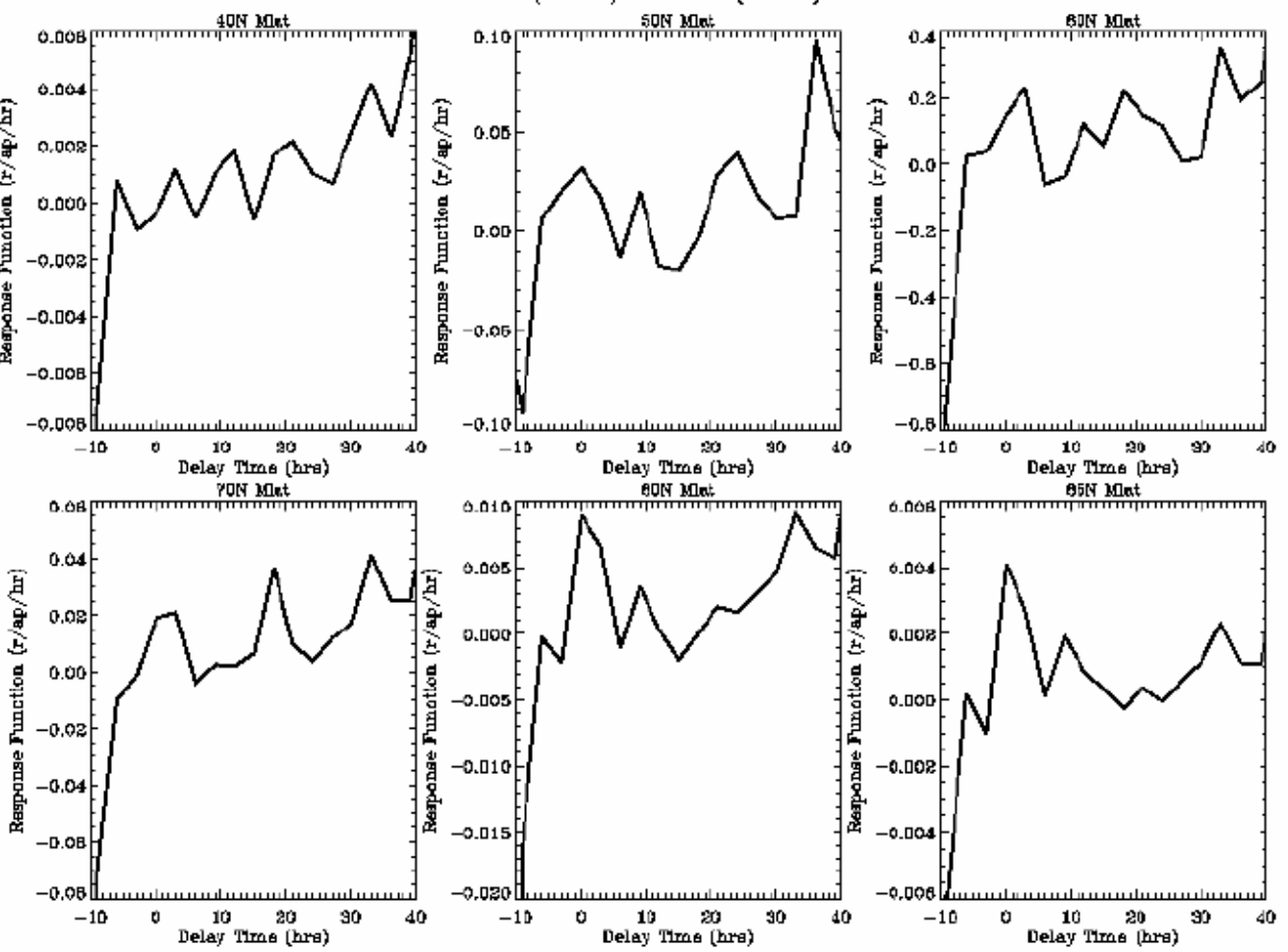

Figure 5: Impulse-response function as a function of delay time (hours) derived from a six day period during the Halloween 2003 storm event. The figure shows the response function derived at several magnetic latitudes. The response function is defined in the text.

\section{ACKNOWLEDGEMENTS}

This material is based upon work supported by the National Aeronautics and Space Administration under grant NNH06DA001N issued through the Science Mission Directorate's Living With A Star Targeted Research and Technology Program.

\section{REFERENCES}

Banks, P. M., C. R. Chappell, and A. F. Nagy, A new model of the interaction of auroral electrons with the atmosphere: Spectral degradation, backscatter, optical emission, and ionization, J. Geophys. Res., 79(10), 1459-1470, 1974.

Bilitza, D., International Reference Ionosphere, Radio Science, 36(2), 261-265, 2001. 
Fox, J. L., and K. Y. Sung, Solar activity variations of the Venus thermosphere/ionosphere, J. Geophys. Res., 106(A10), 21,305-21,335, 2001.

Fuller-Rowell, T. J., E. Araujo-Pradere, and M. V. Codrescu, An empirical ionospheric storm-time correction model, Adv. Space Res., 25(1), 139-146, 2000.

Gordley, L. L., B. T. Marshall, and D. A. Chu, LINEPAK: Algorithms for modeling spectral transmittance and radiance, J. Quant. Spectrosc. Radiat. Transfer, 52(5), 563-580, 1994.

Lopez-Puertas, R. Rodrigo, A. Molina, and F. W. Taylor, A non-LTE radiative transfer model for infrared bands in the middle atmosphere. I. Theoretical basis and application to $\mathrm{CO}_{2} 15 \mu \mathrm{m}$ bands, J. Atmos. Terr. Phys., 48(8), 729-748, $1986 \mathrm{a}$.

Lopez-Puertas, R. Rodrigo, J. J. Lopez-Moreno, and F. W. Taylor, A non-LTE radiative transfer model for infrared bands in the middle atmosphere. II. $\mathrm{CO}_{2}(2.7$ and $4.3 \mu \mathrm{m})$ and water vapor $(6.3 \mu \mathrm{m})$ bands and $\mathrm{N}_{2}(1)$ and $\mathrm{O}_{2}(1)$ vibrational levels, J. Atmos. Terr. Phys., 48(8), 749-764, 1986b.

Lopez-Puertas, M., G. Zaragoza, M. A. Lopez-Valverde, and F. W. Taylor, Non local thermodynamic equilibrium (LTE) atmospheric limb emission at $4.6 \mu \mathrm{m} 1$. An update of the $\mathrm{CO}_{2}$ non-LTE radiative transfer model, J. Geophys. Res., 103(D7), 8499-8513, 1998.

Lopez-Puertas, M., M. Garcia-Comas, B. Funke, R. H. Picard, J. R. Winick, P. P. Wintersteiner, M. G. Mlynczak, C. J. Mertens, J. M. Russell III, and L. L. Gordley, Evidence for an $\mathrm{OH}(\mathrm{v})$ excitation mechanism of $\mathrm{CO} 24.3$ um nighttime emission from SABER/TIMED measurements, J. Geophys. Res., 109, D09307, doi:10.1029/2003JD004383, 2004.

Marshall, B. T., L. L. Gordley, and D. A. Chu, BANDPAK: Algorithms for modeling broadband transmission and radiance, J. Quant. Spectrosc. Radiat. Transfer, 52(5), 581-599, 1994.

Mertens, C. J., M. G. Mlynczak, M. Lopez-Puertas, P. P. Wintersteiner, R. H. Picard, J. R. Winick, L. L. Gordley, and J. M. Russell III, Retrieval of mesospheric and lower thermospheric kinetic temperature from measurements of $\mathrm{CO}_{2} 15 \mu \mathrm{m}$ Earth limb emission under non-LTE condition, Geophys. Res. Lett., 28(7), 1391-1394, 2001.

Mertens, C. J., M. G. Mlynczak, M. Lopez-Puertas, P. P. Wintersteiner, R. H. Picard, J. R. Winick, L. L. Gordley, and J. M. Russell III, Retrieval of kinetic temperature and carbon dioxide abundance from non-local thermodynamic equilibrium limb emission measurements made by the SABER instrument on the TIMED satellite, in Proceedings of SPIE, Remote Sensing of Clouds and the Atmosphere VII, Agia Pelagia, Crete, Greece, September 24-27, vol. 4882, 162-171, 2002.

Mertens, C. J., J. C. Mast, J. R. Winick, J. M. Russell III, M. G. Mlynczak, and D. S. Evans, Ionospheric E-region response to solar-geomagnetic storms obaserved by TIMED/SABER and application to IRI storm-model development, Adv. Space Res., 39, 715-728, 2007.

Mlynczak, M. G., D. K. Zhou, and S. M. Adler-Golden, Kinetic and spectroscopic requirements for the inference of chemical heating rates and atomic hydrogen densities from $\mathrm{OH}$ Meinel band measurements, Geophys. Res. Lett., 25(5), 647-650, 1998. 
Picone, J. M., A. E. Hedin, D. P. Drob, and A. C. Aikin, NRLMSIS-00 empirical model of the atmosphere: Statistical comparisons and scientific issues, J. Geophys. Res., 107(A12), 1468, doi:10.1029/2002JA009430, 2002.

Press, W. H., S. A. Teukolsky, W. T. Vetterling, and B. P. Flannery, Numerical Recipes in FORTRAN: The Art of Scientific Computing, Cambridge University Press, New York, 1992.

Roble, R. G., Energetics of the mesosphere and thermosphere, in The Upper Mesosphere and Lower Thermosphere: A Review of Experiment and Theory, AGU Monogr. Ser., vol. 87, edited by R. M. Johnson and T. L. Killeen, American Geophysical Union, Washington DC., 1995.

Russell, J. M., III, M. G. Mlynczak, L. L. Gordley, J. Tansock, and R. Esplin, An overview of the SABER experiment and preliminary calibration results, in Proceedings of the SPIE, $44^{\text {th }}$ Annual Meeting, Denver, Colorado, July 18-23, vol. 3756, pp. 277-288, 1999.

Strickland, D. J., D. L. Book, T. P. Coffey, and J. A. Fedder, Transport equation techniques for the deposition of auroral electrons, J. Geophys. Res., 81(16), 27552764, 1976.

Torr, M. R., D. G. Torr, P. G. Richards, and S. P. Yung, Mid- and low-latitude model of thermospheric emissions $1 . \mathrm{O}^{+}\left({ }^{2} \mathrm{P}\right) 7320 \mathrm{~A}$ and $\mathrm{N}_{2}\left({ }^{2} \mathrm{P}\right) 3371 \mathrm{~A}, \mathrm{~J}$. Geophys. Res., 95(A12), 21,147-21,168, 1990.

Vassiliadis, D., A. J. Klimas, S. G. Kanekal, D. N. Baker, and R. S. Weigel, Long-termaverage, solar cycle, and seasonal response of magnetispheric energetic electrons to the solar wind speed, J. Geophys. Res.,107(A11), 1383, doi:10.1029/2001JA000506, 2002.

Winick, J. R., R. H. Picard, R. A. Joseph, R. D. Sharma, and P. P. Wintersteiner, An infrared spectral radiance code for the auroral thermosphere (AARC), Rep. AFGLTR-87-0334, Air Force Geophysical Laboratory, Hanscom Air Force Base, Massachusetts, 1987. 